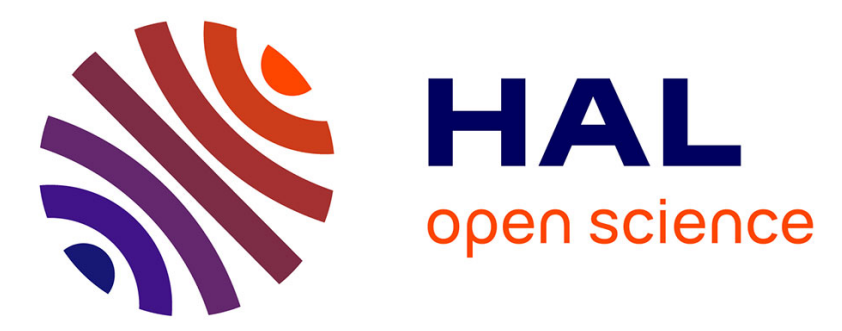

\title{
Plasma long-chain omega-3 fatty acids and atrophy of the medial temporal lobe.
}

\author{
Cécilia Samieri, Pauline Maillard, Fabrice Crivello, Cécile Proust-Lima, \\ Evelyne Peuchant, Catherine Helmer, Helene Amieva, Michele Allard, \\ Jean-Francois Dartigues, Stephen C Cunnane, et al.
}

\section{To cite this version:}

Cécilia Samieri, Pauline Maillard, Fabrice Crivello, Cécile Proust-Lima, Evelyne Peuchant, et al.. Plasma long-chain omega-3 fatty acids and atrophy of the medial temporal lobe.. Neurology, 2012, 79, pp.642-50. hal-01164730

\section{HAL Id: hal-01164730 \\ https://hal.science/hal-01164730}

Submitted on 17 Jun 2015

HAL is a multi-disciplinary open access archive for the deposit and dissemination of scientific research documents, whether they are published or not. The documents may come from teaching and research institutions in France or abroad, or from public or private research centers.
L'archive ouverte pluridisciplinaire HAL, est destinée au dépôt et à la diffusion de documents scientifiques de niveau recherche, publiés ou non, émanant des établissements d'enseignement et de recherche français ou étrangers, des laboratoires publics ou privés.

\section{다)(1) $(5$}

Distributed under a Creative Commons Attribution - NonCommercial| 4.0 International 
Cécilia Samieri, PhD

Pauline Maillard, PhD

Fabrice Crivello, PhD

Cécile Proust-Lima, PhD

Evelyne Peuchant, MD,

$\mathrm{PhD}$

Catherine Helmer, MD,

$\mathrm{PhD}$

Helene Amieva, PhD

Michele Allard, MD, PhD

Jean-Francois Dartigues,

$\mathrm{MD}, \mathrm{PhD}$

Stephen C. Cunnane,

$\mathrm{PhD}$

Bernard M. Mazoyer,

$\mathrm{MD}, \mathrm{PhD}$

Pascale Barberger-Gateau,

$\mathrm{MD}, \mathrm{PhD}$

Correspondence \& reprint requests to Dr. Samieri: Cecilia.Samieri@isped.ubordeaux2.fr

Supplemental data at www.neurology.org

\section{Plasma long-chain omega-3 fatty acids and atrophy of the medial temporal lobe}

\section{ABSTRACT}

Objective: The long-chain $\omega$-3 fatty acids eicosapentaenoic acid (EPA) and docosahexaenoic acid (DHA) are potential candidates for interventions to delay Alzheimer disease (AD), but evidence from clinical studies is mixed. We aimed at determining whether plasma levels of EPA or DHA predict atrophy of medial temporal lobe (MTL) gray matter regions in older subjects.

Methods: A total of 281 community dwellers from the Three-City Study, aged 65 years or older, had plasma fatty acid measurements at baseline and underwent MRI examinations at baseline and at 4 years. We studied the association between plasma EPA and DHA and MTL gray matter volume change at 4 years.

Results: Higher plasma EPA, but not DHA, was associated with lower gray matter atrophy of the right hippocampal/parahippocampal area and of the right amygdala $(p<0.05$, familywise error corrected). Based on a mean right amygdala volume loss of $6.0 \mathrm{~mm}^{3} / \mathrm{y}(0.6 \%)$, a $1 \mathrm{SD}$ higher plasma EPA $\left(+0.64 \%\right.$ of total plasma fatty acids) at baseline was related to a $1.3 \mathrm{~mm}^{3}$ smaller gray matter loss per year in the right amygdala. Higher atrophy of the right amygdala was associated with greater 4-year decline in semantic memory performances and more depressive symptoms.

Conclusion: The amygdala, which develops neuropathology in the early stage of $A D$ and is involved in the pathogenesis of depression, may be an important brain structure involved in the association between EPA and cognitive decline and depressive symptoms. Neurology ${ }^{\circledR}$ 2012;79:642-650

\section{GLOSSARY}

3C = Three-City; AD = Alzheimer disease; CES-D = Center for Epidemiologic Studies-Depression; $\mathbf{D H A}=$ docosahexaenoic acid; DSM-IV = Diagnostic and Statistical Manual of Mental Disorders, 4th edition; EPA = eicosapentaenoic acid; GM = gray matter; IST = Isaacs Set Test; MMSE = Mini-Mental State Examination; MTL = medial temporal lobe; $\mathbf{n}-\mathbf{3}$ PUFA $=\omega-3$ polyunsaturated fatty acids; $\mathbf{n}-\mathbf{6}$ PUFA $=\omega$ - 6 polyunsaturated fatty acids; TIV $=$ total intracranial volume; $\mathbf{W M}=$ white matter.

The long-chain $\omega$-3 polyunsaturated fatty acids (n-3 PUFA) eicosapentaenoic acid (EPA) and docosahexaenoic acid (DHA) in fish are promising candidates for prevention of sporadic Alzheimer disease (AD). ${ }^{1,2}$ DHA is a major component of neuron membranes where it exerts a structural and functional role. EPA is present in the brain in much lower amounts than DHA but, like DHA, may also have neuroprotective properties through anti-inflammatory, antioxidant, and energy metabolism pathways. ${ }^{2}$

Several prospective epidemiologic studies directly link higher fish consumption, or higher blood status of EPA or DHA, to lower risk of dementia, AD, or cognitive decline. ${ }^{1,2}$ However, to date, most clinical trials using fish oil or DHA supplements have been inconclusive. ${ }^{2-5}$ More evidence for a specific neurotherapeutic target of EPA and DHA is therefore needed, based

\footnotetext{
From the Equipe "Epidemiologie de la nutrition et des comportements alimentaires" (C.S., P.B.-G.), Equipe "Biostatistiques" (C.P.-L.), and Equipe "Epidémiologie et neuropsychologie du vieillissement cerebral” (C.H., H.A., J.-F.D.), Centre INSERM U897-Epidemiologie-Biostatistique, Bordeaux, France; INSERM (C.S., C.P.-L., C.H., H.A., J.-F.D., P.B.-G.), ISPED, Centre INSERM U897-Epidemiologie-Biostatistique, Bordeaux; University of Bordeaux (C.S., C.P.-L., C.H., H.A., J.-F.D., P.B.-G.), ISPED, Centre INSERM U897-Epidemiologie-Biostatistique, Bordeaux; CNRS (P.M.), CI-NAPS, UMR6232, Caen, France; CEA (P.M.), DSV/I2BM/CI-NAPS, Caen; University of Caen Basse-Normandie (P.M.), Caen; CNRS (F.C., B.M.M.), GIN, UMR 5296, Bordeaux; CEA (F.C., B.M.M.), GIN, UMR 5296, Bordeaux; University of Bordeaux (F.C., B.M.M.), GIN, UMR 5296, Bordeaux; INSERM (E.P.), INSERM U876, Bordeaux; CHU de Bordeaux (E.P.), Hôpital Saint-André, Département de Biochimie, INSERM U876, Bordeaux; Neurofunctional and Cognitive Imaging Team (M.A.), CNRS/UB1/UB2 Unit, Bordeaux; CNRS (M.A.), CNRS/UB1/ UB2 Unit, Bordeaux; University of Bordeaux (M.A.), CNRS/UB1/UB2 Unit, Bordeaux; CHU de Bordeaux (M.A.), Service de Médecine Nucléaire, CNRS/UB1/UB2 Unit, Bordeaux; and Research Center on Aging (S.C.C.), Université de Sherbrooke, Sherbrooke, Canada. Study funding: Funding information is provided at the end of the article.

Go to Neurology.org for full disclosures. Disclosures deemed relevant by the authors, if any, are provided at the end of this article.
} 
on validated biomarkers of $\mathrm{AD}$, such as atrophy of medial temporal lobe (MTL) structures. In older subjects, lower red blood cell EPA+DHA levels were recently shown to correlate with smaller brain volumes. ${ }^{6}$ However, to our knowledge, the association between plasma EPA and DHA and brain atrophy has not been explored using a longitudinal design.

The primary objective of this populationbased MRI study was to examine whether plasma EPA or DHA were associated with whole brain and MTL-specific gray matter (GM) volume change over 4 years. Secondly, we sought to determine whether GM volume change in the MTL regions involved in such relationship was associated with a decline of cognitive performance or an increase of depressive symptoms during follow-up.

METHODS Study population. The present study is based on the Bordeaux sample of the Three-City (3C) Study, a prospective cohort study of vascular risk factors for dementia which started in 1999-2000 and included 9,294 noninstitutionalized community dwellers aged $\geq 65$ years in Bordeaux $(n=2,104)$, Dijon $(n=4,931)$, and Montpellier $(n=2,259)$, France. Details of the study were described previously. ${ }^{7}$ Baseline data collection included sociodemographic and lifestyle characteristics, symptoms and complaints, main chronic conditions, neuropsychological testing, physical examination, and blood sampling. Four follow-up examinations were performed 2, 4, 7, and 10 years after baseline. The present study is based on the first 4 years of follow-up.

In Bordeaux, plasma fatty acids were measured at baseline in 1,419 participants (figure e- 1 on the Neurology ${ }^{\circledR}$ Web site at www.neurology.org). Among them, 504 individuals also underwent a brain MRI examination. At 4 years, 315 participants underwent a second MRI examination. We excluded 30 participants with unusable scans and 4 with missing data for main covariates, leaving 281 participants available for the present study.

Standard protocol approvals, registrations, and patient consents. The protocol of the $3 \mathrm{C}$ study has been approved by the Consultative Committee for the Protection of Persons participating in Biomedical Research of the Kremlin-Bicêtre University Hospital (Paris). All participants gave their written informed consent.

MRI data. MRI acquisition. The MRI acquisition was performed on a 1.5-T Magnetom (Siemens, Erlangen, Germany). A $3 \mathrm{D}$, high-resolution $\mathrm{T} 1$-weighted brain image was acquired using a $3 \mathrm{D}$ inversion recovery fast spoiled-gradient echo sequence. T2- and proton density-weighted brain volumes were acquired during the same sequence using a $2 \mathrm{D}$ dual spin echo sequence with 2 echo times (e-Methods).

MRI processing. Using the multi-spectral segmentation scheme implemented in SPM8 (Statistical Parametric Mapping, release 8$),{ }^{8}$ baseline T1 and T2 images were first segmented into GM, white matter (WM), and CSF images and then spatially normalized using a 3C template (e-Methods). Probability maps were smoothed using a $12-\mathrm{mm}$ full width at half-maximum isotropic Gaussian kernel.

Whole brain and MTL volumes estimation. A so-called modulation $^{8}$ was applied to the resulting individual GM, WM, and CSF probability maps to preserve the subject's original tissue quantity after its transfer to the reference space. Baseline and 4-year GM, WM, and CSF volumes were computed as the integral of the voxel intensities in the corresponding modulated tissue image, and total intracranial volume (TIV) was defined as their sum. Baseline and 4-year MTL volumes were automatically computed within the MTL limits derived from a model of macroscopic neuroanatomic parcellation. ${ }^{9,10}$ Three MTL structures were selected: 1) the hippocampal region consisting of the dentate gyrus, the uncus, and the hippocampus; 2) the parahippocampal region consisting of the parahippocampal gyrus; and 3) the parahippocampal uncus, both including entorhinal and perirhinal cortices, and the amygdala.

The individual annual rates of GM volume change were defined as the difference between the 4-year and baseline GM volumes divided by the time between the 2 MRI examinations. Probability maps of annual GM change ( $\Delta / \mathrm{y}$ GM map) were calculated as the difference between 4-year and baseline GM probability maps divided by the time between the 2 MRI examinations.

Clinical data. Cognitive assessment. The psychologists administered a battery of neuropsychological tests at baseline and at each follow-up examination. In the present study, we were interested in the Mini-Mental State Examination (MMSE), ${ }^{11}$ an index of global cognitive performance (range $0-30$ ), and the Isaacs Set Test (IST), ${ }^{12}$ which assesses semantic verbal fluency and begins to decline very early in the prodromal phase of $\mathrm{AD} .{ }^{13}$ For the IST, participants have to generate a list of words belonging to a specific semantic category in 15 seconds. Four semantic categories are successively used (cities, fruits, animals, and colors) (range 0-53).

Diagnosis of dementia was based on a 3-step procedure. ${ }^{7}$ All potential incident cases of dementia were reviewed by an independent committee of neurologists to obtain a consensus on the diagnosis and etiology according to the criteria of the DSM-IV..$^{14}$

Assessment of depressive symptoms. Depressive symptoms were recorded by trained psychologists at baseline and at the 2-year and 4-year visits with the validated Center for Epidemiologic Studies-Depression (CES-D) scale. ${ }^{15,16}$ Scores range from 0 to 60 according to the frequency of the depressive symptoms during the previous week. High depressive symptoms were defined as a CES-D score of $\geq 17$ in men and $\geq 23$ in women, as validated in a French population. ${ }^{17}$

Plasma fatty acids. Plasma fatty acid composition was determined from fasting blood samples collected at baseline, as previously detailed ${ }^{18}$ (e-Methods). For this study, the focus was on plasma EPA and DHA proportions (in percentage of total fatty acids), transformed into $Z$ scores. In supplementary analyses, we also considered total n-3 PUFA (as the sum of $\alpha$-linolenic acid + docosapentaenoic acid + EPA + DHA), total $\omega-6$ polyunsaturated fatty acids (n-6 PUFA) (as the sum of linoleic acid + $\gamma$-linolenic acid + arachidonic acid), as well as total PUFA (as the sum of n-3 and n-6 PUFA).

Other variables. Sociodemographic variables included age, sex, and education. APOE4 allele carrier status was considered dichotomously (at least $1 \epsilon 4$ allele vs no $\epsilon 4$ allele). Vascular risk factors at baseline included smoking, history of cardiovascular or cerebrovascular disease, hypertension (if systolic blood pressure $\geq 140 \mathrm{mmHg}$ or diastolic blood pressure $\geq 90 \mathrm{~mm} \mathrm{Hg}$, or anti- 
hypertensive medication), hypercholesterolemia (if plasma total cholesterol $\geq 6.20 \mathrm{mmol} / \mathrm{L}$, or cholesterol-lowering medication), diabetes (if fasting glycemia $\geq 7.0 \mathrm{mmol} / \mathrm{L}$, or antidiabetic medication), body mass index (body weight $/ \mathrm{height}^{2}\left[\mathrm{~kg} / \mathrm{m}^{2}\right]$ ), triglyceridemia, and usual alcohol consumption.

In Bordeaux, a detailed food frequency questionnaire was administered at the 2-year and 4-year visits; the stability of fish consumption between these 2 periods was assessed within each quartile of baseline plasma EPA and DHA (e-Methods).

Statistical analyses. Statistical analyses at the voxel level: $V B M$. Whether plasma long-chain n-3 PUFA was associated with the probability of GM was tested in each voxel. Using the smoothed normalized GM maps, multiple linear regressions were performed in the MTL to assess associations between baseline EPA or DHA plasma proportion and annual GM change, adjusting for baseline age, gender, education, and APOE4 status. The threshold was set at $p<0.05$ (familywise error-corrected for multiple comparisons). In additional models, we secondarily considered total n-3, total n-6 PUFA, as well as total PUFA.

Statistical analyses at the global level. Individual estimations of GM volumes in each MTL structure of interest were used to investigate, when significant in VBM, 1) associations between EPA or DHA or total PUFA and annual change in GM, taking into account a broader set of adjusting variables, and 2) whether GM volume change in the regions involved was associated with a decline of cognitive performance or an increase in depressive symptoms. SAS statistical software (release 9.1, SAS institute Inc, Cary, NC) and lcmm $R$ package ${ }^{19}$ were used, and statistical tests were computed at the $\alpha=0.05$ level of significance.

Association between plasma n-3 PUFA and MRI data. For each MTL structure, GM volume change was described using linear mixed models. ${ }^{20}$ The mean trajectory of GM change was modeled as a linear trend with the baseline mean GM volume (intercept) and the annual change in GM volume (slope) allowed varying with the PUFA of interest. Interindividual variability was accounted for through correlated subject-specific random intercept and slope. Three different adjusted models were constructed which respectively included as covariates: 1) TIV, age, gender, education, and APOE4 status (model 1), 2) and depressive symptoms and vascular risk factors (model 2), 3) and whole brain GM volume change (model 3).

Association between MRI data and clinical data. For each MTL structure significantly associated with n-3 PUFA, we further examined whether annual GM volume change ( $\Delta / \mathrm{y}$ GM volume) was associated with the evolution of cognitive performances and depressive symptoms during the same period, using latent process mixed models that, compared to standard linear mixed models, correct for the curvilinearity of the tests/scales. ${ }^{19,21}$ Change of the latent process underlying MMSE, IST, and CES-D scores was modeled as an individual-specific linear trend (with random intercept and slope). Association with $\Delta / \mathrm{y}$ GM volume was assessed on the slope only, while associations with other covariates (baseline GM volume of the MTL structure, age, gender, education, and TIV) were evaluated both on the intercept and the slope of the underlying latent process.

RESULTS Participants were 72.3 years old, $42.2 \%$ were male, and mean MMSE score was 27.9 (table 1). Baseline plasma EPA and DHA were associated with frequency of fish consumption at 2 and 4 years, and within each quartile of plasma EPA, mean frequency of fish consumption remained stable during

\section{Table 1 Baseline characteristics of the participants: The Bordeaux sample \\ of the Three-City Study $(n=281)$}

\begin{tabular}{|c|c|}
\hline Characteristics & Values \\
\hline Age, $y$, mean (SD) & $72.3(3.8)$ \\
\hline Male, n (\%) & $119(42.3)$ \\
\hline \multicolumn{2}{|l|}{ Educational level, $n$ (\%) } \\
\hline None or primary & 67 (23.8) \\
\hline Secondary & $73(26.0)$ \\
\hline High school & $70(24.9)$ \\
\hline University & $71(25.3)$ \\
\hline APOE4+, ${ }^{a}$ (\%) & 64 (22.8) \\
\hline BMI, mean (SD) & 26.2 (3.8) \\
\hline \multicolumn{2}{|l|}{ Smoking, $n(\%)$} \\
\hline Never & $176(62.6)$ \\
\hline Former & $91(32.4)$ \\
\hline Current & $14(5.0)$ \\
\hline $\begin{array}{l}\text { No. of glasses of alcoholic } \\
\text { beverages per week, mean (SD) }\end{array}$ & $14.6(16.7)$ \\
\hline $\begin{array}{l}\text { History of cardiovascular } \\
\text { disease, } \mathrm{n}(\%)\end{array}$ & 29 (10.3) \\
\hline Diabetes, $^{b} \mathrm{n}(\%)$ & $23(8.2)$ \\
\hline Hypercholesterolemia, ${ }^{c}$ (\%) & $166(59.1)$ \\
\hline Hypertension, $n(\%)$ & $168(59.8)$ \\
\hline Triglycerides, $^{\mathrm{C}} \mathrm{mmol} / \mathrm{L}$, mean (SD) & $1.2(0.6)$ \\
\hline CES-D score, median (Q1-Q3) & $4(1-8)$ \\
\hline MMSE score, mean (SD) & $27.9(1.8)$ \\
\hline $\begin{array}{l}\text { EPA, \% total fatty acids, mean (SD) } \\
\text { (range) }\end{array}$ & $1.1(0.6)(0.3-5.0)$ \\
\hline $\begin{array}{l}\text { DHA, \% total fatty acids, mean (SD) } \\
\text { (range) }\end{array}$ & $2.4(0.8)(0.6-5.7)$ \\
\hline
\end{tabular}

Abbreviations: $\mathrm{BMI}=$ body mass index; $\mathrm{CES}-\mathrm{D}=$ Center for Epidemiologic Studies-Depression scale; DHA = docosahexaenoic acid; EPA = eicosapentaenoic acid; MMSE = Mini-Mental State Examination.

a APOE 4 carriers (at least one $\epsilon 4$ allele) were noted as APOE4+.

b Data missing for 3 participants.

c Data missing for 1 participant.

follow-up (e-Results and table e-1). Fish consumption remained stable over the 4 years in the extreme quartiles of plasma DHA, and slightly increased in the intermediate quartiles. The subjects who agreed to have MRI were healthier than those who did not, including having better nutritional status (e-Results).

Association between plasma long-chain n-3 PUFA and MRI data. The mean rate of GM atrophy from baseline was $-0.2 \% / y$ in the whole brain. In the MTL, it ranged from $-0.5 \% / y$ for the left amygdala to $-1.0 \% / y$ for the left hippocampus (table 2).

On a voxel-by-voxel basis, higher baseline plasma EPA was significantly associated with less GM atrophy in a region of which $53 \%$ was the right amygdala, $41 \%$ was the right parahippocampus, and 


\begin{tabular}{|c|c|c|c|}
\hline \multicolumn{4}{|c|}{$\begin{array}{l}\text { Mean baseline GM volume and rate of change of GM in the whole brain and in MTL regions } \\
\text { of interest }\end{array}$} \\
\hline \multirow[t]{2}{*}{ Whole brain } & $\begin{array}{l}\text { Baseline GM volume }\left(\mathrm{cm}^{3}\right) \text {, } \\
\text { mean (SD) }\end{array}$ & $\begin{array}{l}\text { GM volume change }\left(\mathrm{cm}^{3} / y\right) \text {, } \\
\text { mean (SD) }\end{array}$ & $\begin{array}{l}\text { GM rate of change from baseline }(\% / y) \text {, } \\
\text { mean (SD) }\end{array}$ \\
\hline & $520.6(50.6)$ & $-0.8(1.4)$ & $-0.2(0.3)$ \\
\hline Regions of interest & Baseline $\mathrm{GM}$ volume $\left(\mathrm{mm}^{3}\right)$ & $\mathrm{GM}$ volume change $\left(\mathrm{mm}^{3} / \mathrm{y}\right)$ & GM rate of change from baseline $(\% / y)$ \\
\hline Left hippocampus & $3,979.0(433.7)$ & $-40.8(31.0)$ & $-1.0(0.8)$ \\
\hline Right hippocampus & 3,605.2 (414.3) & -32.4 (26.9) & $-0.9(0.8)$ \\
\hline $\begin{array}{l}\text { Left parahippocampal } \\
\text { region }^{a}\end{array}$ & $3,578.6$ (361.9) & $-20.4(26.6)$ & $-0.6(0.7)$ \\
\hline $\begin{array}{l}\text { Right parahippocampal } \\
\text { region }^{a}\end{array}$ & $4,547.2(483.5)$ & $-26.0(34.5)$ & $-0.6(0.8)$ \\
\hline Left amygdala & $940.4(92.0)$ & $-4.2(8.5)$ & $-0.5(0.9)$ \\
\hline Right amygdala & $977.3(102.1)$ & $-6.0(8.4)$ & $-0.6(0.9)$ \\
\hline
\end{tabular}

Abbreviations: $\mathrm{GM}=$ gray matter; $\mathrm{MTL}=$ medial temporal lobe.

a Consisted of the parahippocampal gyrus and the parahippocampal uncus, both including entorhinal and perirhinal cortices.

$6 \%$ was the right hippocampus (figure 1). More than $45 \%$ of the whole right amygdala, but $<10 \%$ of the whole right hippocampal/parahippocampal area, were included in this cluster. In contrast to plasma EPA, plasma DHA, as well as plasma total PUFA, total n-3, and total n-6 PUFA, were not significantly associated with GM volume change (data not shown). When plasma EPA and DHA were introduced together in a same model, higher EPA but not
DHA was associated with less GM atrophy in the aforementioned brain region (data not shown).

At the global level, higher plasma EPA was significantly associated with less GM atrophy of the right amygdala (whole structure) over 4 years, but not with the 4-year change in the volume of the other MTL regions (table 3) or of the whole brain (table e-2). This association remained significant after adjustment for vascular risk factors, depressive symptoms (model 2),

Figure 1 Specific area of lower gray matter atrophy over 4 years within the medial temporal lobe with each $1 \mathrm{SD}$ increase of plasma eicosapentaenoic acid, after adjustment for age, gender, education, APOE4 carrier status, and correcting for total intracranial volume $(n=281)$
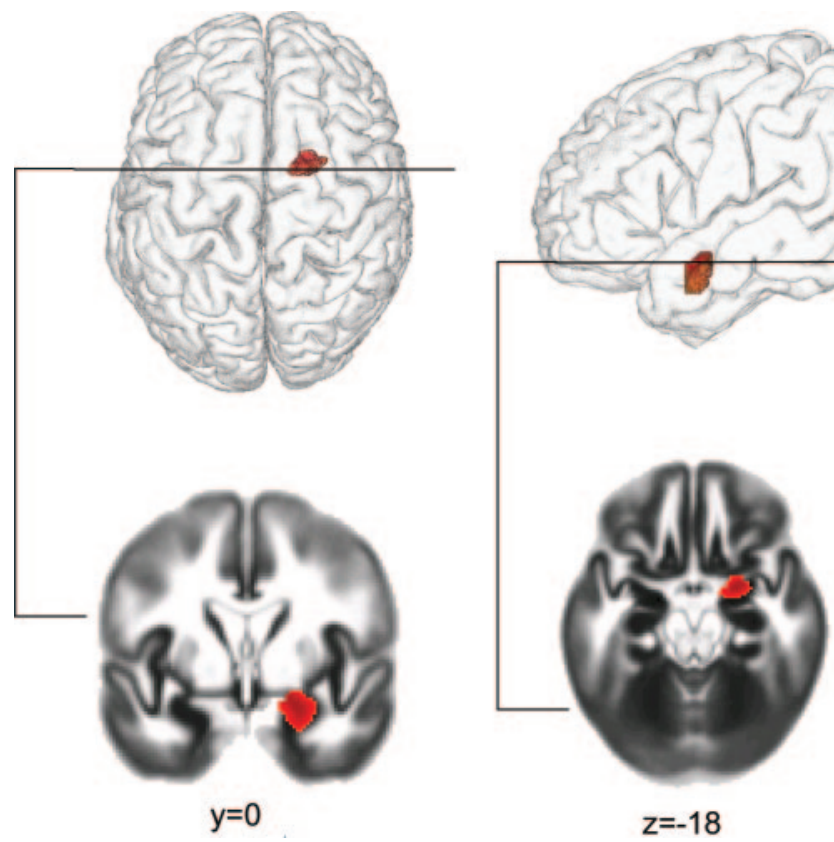

T

Student $t$ map is superimposed onto the gray matter probability map, displayed at $p<0.05$ familywise error corrected for multiple comparisons. The $x, y$, and $z$ coordinates $(\mathrm{mm})$ give the slice location in stereotactic space. The region of interest included the hippocampal region consisting of the dentate gyrus, the uncus, and the hippocampus, the parahippocampal region consisting of the parahippocampal gyrus and the parahippocampal uncus, both including entorhinal and perirhinal cortices, and the amygdala. 
Table 3 Multivariate associations ${ }^{a}$ between baseline plasma EPA and GM volume change $\left(\mathrm{mm}^{3} / \mathrm{y}\right)$ over 4 years in MTL regions of interest

\begin{tabular}{|c|c|c|c|c|c|c|}
\hline & \multicolumn{2}{|c|}{ Model $1(n=281)$} & \multicolumn{2}{|c|}{ Model $2(n=275)$} & \multicolumn{2}{|c|}{ Model $3(n=275)$} \\
\hline & $\beta$ (SE) & $p$ & $\beta$ (SE) & $p$ & $\beta$ (SE) & $p$ \\
\hline \multicolumn{7}{|c|}{ Left hippocampus } \\
\hline EPA & $12.0(14.8)$ & 0.42 & 9.7 (15.2) & 0.52 & 9.8 (15.2) & 0.52 \\
\hline$E P A \times$ time & $-0.1(1.9)$ & 0.96 & $0.4(2.0)$ & 0.82 & $0.1(1.9)$ & 0.95 \\
\hline \multicolumn{7}{|c|}{ Right hippocampus } \\
\hline EPA & $6.2(15.7)$ & 0.69 & $12.6(15.8)$ & 0.42 & 12.6 (15.8) & 0.43 \\
\hline$E P A \times$ time & $1.7(1.7)$ & 0.31 & $1.9(1.7)$ & 0.26 & $1.7(1.7)$ & 0.31 \\
\hline \multicolumn{7}{|c|}{ Left parahippocampal region ${ }^{\mathrm{b}}$} \\
\hline EPA & 7.8 (13.2) & 0.55 & $8.4(13.6)$ & 0.53 & $8.5(13.6)$ & 0.53 \\
\hline EPA $\times$ time & $0.1(1.6)$ & 0.94 & $0.3(1.7)$ & 0.85 & $-0.1(1.6)$ & 0.97 \\
\hline \multicolumn{7}{|c|}{ Right parahippocampal region ${ }^{b}$} \\
\hline EPA & $3.9(18.1)$ & 0.83 & $16.6(18.4)$ & 0.37 & $16.6(18.4)$ & 0.37 \\
\hline EPA $\times$ time & 0.9 (2.2) & 0.66 & $1.0(2.2)$ & 0.65 & $0.6(2.2)$ & 0.78 \\
\hline \multicolumn{7}{|l|}{ Left amygdala } \\
\hline EPA & $4.3(3.5)$ & 0.21 & $4.8(3.6)$ & 0.18 & $4.8(3.6)$ & 0.18 \\
\hline EPA $\times$ time & $0.5(0.5)$ & 0.38 & $0.7(0.5)$ & 0.17 & $0.6(0.5)$ & 0.22 \\
\hline \multicolumn{7}{|c|}{ Right amygdala } \\
\hline EPA & 3.7 (3.9) & 0.34 & $4.7(4.0)$ & 0.25 & $4.7(4.0)$ & 0.25 \\
\hline EPA $\times$ time & $1.2(0.5)$ & 0.02 & $1.4(0.5)$ & 0.01 & $1.3(0.5)$ & 0.01 \\
\hline
\end{tabular}

Abbreviations: $\mathrm{EPA}$ = eicosapentaenoic acid; GM = gray matter; MTL = medial temporal lobe.

a Estimated using separate linear mixed models. $\beta$ coefficients are expressed for 1 SD increase of plasma proportion of total fatty acids. Model 1: adjusted for baseline total intracranial volume, age, education, gender, APOE4 carrier status, and their interactions with time. Model 2: Model 1 + depressive symptoms, body mass index, tobacco use, alcohol consumption, history of cardiovascular and cerebrovascular disease, hypertension, hypercholesterolemia, diabetes, triglyceridemia, and their interactions with time. Model 3: Model $2+$ whole brain GM volume change $\times$ time.

b Consisted of the parahippocampal gyrus and the parahippocampal uncus, both including entorhinal and perirhinal cortices.

and whole brain GM volume change (model 3). The results were virtually unchanged after excluding the 13 stroke cases ( 9 prevalent at baseline, 4 incident) or the 4 dementia cases (1 prevalent, 3 incident).

Association between annual GM change in the amygdala and clinical data. Greater 4-year atrophy of the left amygdala was significantly associated with greater MMSE score decline (figure 2A). Greater left and right amygdala atrophy was associated with greater IST decline (figure 2, C and D). Finally, greater atrophy of the right amygdala was associated with increased CES-D scores over time (figure 2F). In this sample, higher plasma EPA or DHA were not significantly associated with change in MMSE, IST, or CES-D scores.

DISCUSSION In the present study, higher baseline plasma EPA but not DHA was associated with less GM atrophy over 4 years of both the right amygdala and part of the right hippocampal/parahippocampal area. At the global level, only the association between plasma EPA and GM atrophy of the right amygdala was statistically significant. After adjustment for potential confounders, and based on a mean right amygdala volume loss of $-6.0 \mathrm{~mm}^{3} / \mathrm{y}(0.6 \%)$, a 1 SD higher plasma EPA $(+0.64 \%$ of total plasma fatty acids) at baseline was related to a $1.3 \mathrm{~mm}^{3}$ smaller GM loss per year in the right amygdala, independently of the degree of whole brain GM atrophy. Furthermore, more atrophy of the right amygdala was associated with higher decline in semantic memory performance, and, specifically, with increased symptoms of depression during the 4-year follow-up.

In our study, neither plasma EPA nor DHA were significantly associated with change in whole brain GM volume. This result is consistent with the Cardiovascular Health Study and the Oregon Brain Aging Study, both of which did not find any significant relation of fish consumption or marine $\omega-3$ nutrient biomarker pattern, respectively, to whole brain volumes. ${ }^{22,23}$ Conversely, the Framingham Study recently reported an association between lower red blood cell DHA and smaller whole brain volume. ${ }^{6}$ Our results are, however, very similar to a previous 
Figure 2 Evolution of predicted scores on the MMSE, the IST, and the CES-D scale over 4 years as a function of annual GM volume change of the left and right amygdala $(n=281)$

GM volume change

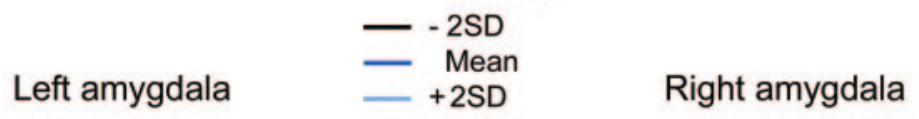

A

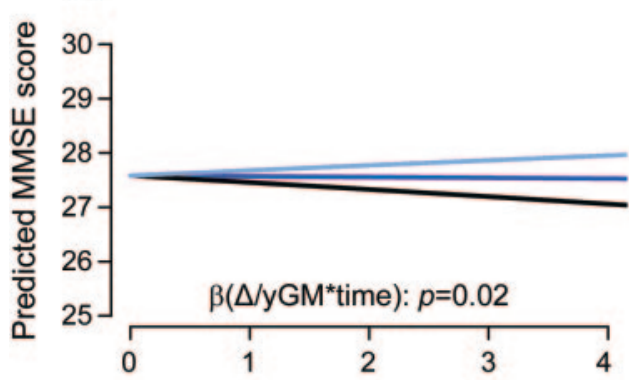

C

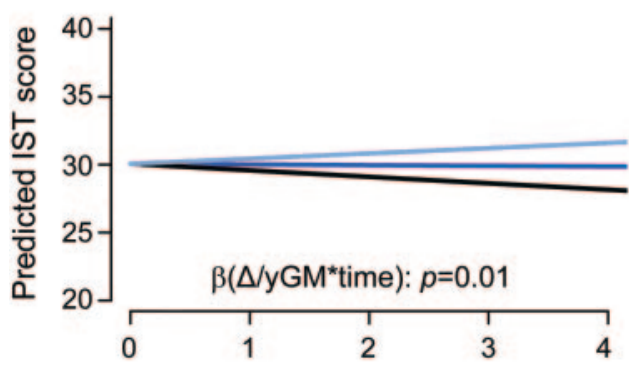

E

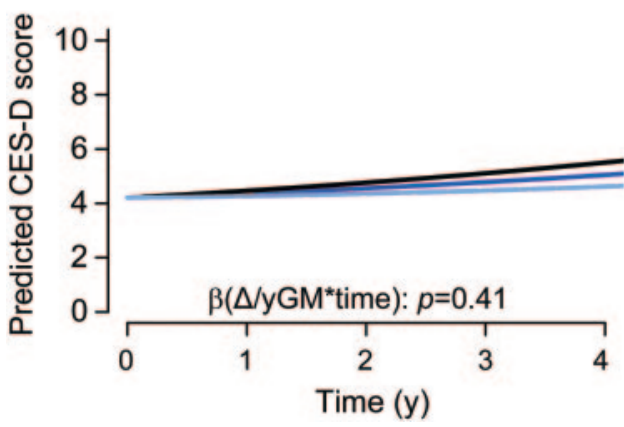

B

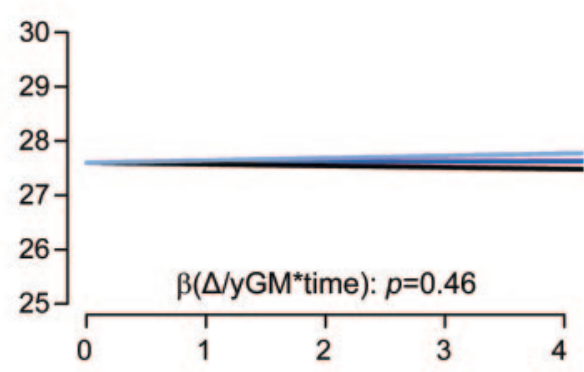

D

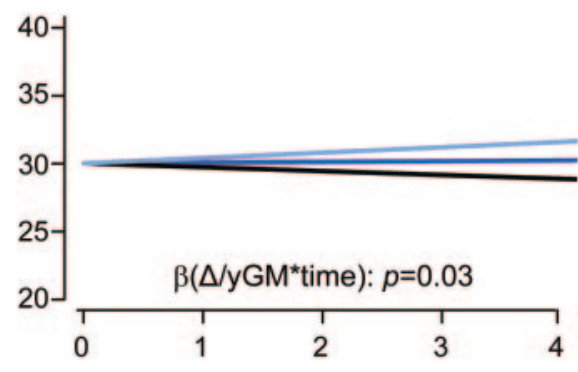

$\mathrm{F}$

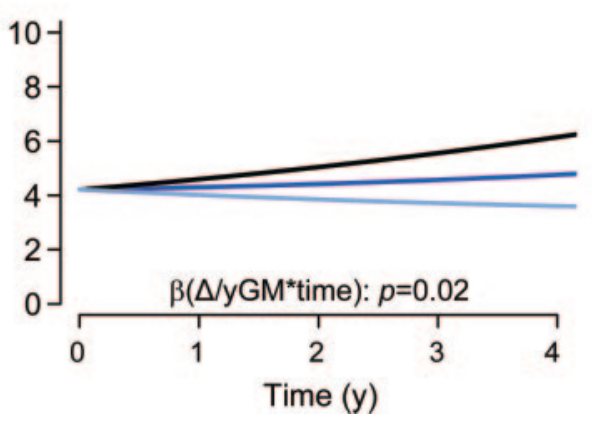

Latent process mixed models were used to describe the repeated measures of individual scores on the Mini-Mental State Examination (MMSE), the Issacs Set Test (IST), and the Center for Epidemiologic Studies-Depression (CES-D) scale function of time, baseline amygdala gray matter (GM) volume, baseline amygdala GM volume $\times$ time, $\Delta / y$ amygdala GM volume $\times$ time, age, age $\times$ time, gender, gender $\times$ time, education, education $\times$ time, APOE4, APOE4 $\times$ time, total intracranial volume (TIV), TIV $\times$ time. $\Delta / y$ GM volume refers to annual GM change in the amygdala. The left and the right amygdala were included in separate models. The regressions were run in the scale of the latent process underlying the individual scores, and predicted scores were computed in the scale of each psychometric test. Predicted mean evolution of MMSE, IST, and CES-D scores were represented for a man, 65 years old, low level of education (no or primary), non-APOE4 carrier, mean total intracranial volume $\left(1,205 \mathrm{~mm}^{3}\right)$ and mean baseline GM volume of the amygdala (respectively: left amygdala, $940.4 \mathrm{~mm}^{3}$ and right amygdala: $977.3 \mathrm{~mm}^{3}$ ). Panels A and B refer to the evolution of predicted MMSE score as a function of GM volume change of the left and right amygdala, respectively. Panels $\mathrm{C}$ and $\mathrm{D}$ refer to the evolution of predicted IST score as a function of GM volume change of the left and right amygdala, respectively. Panels $E$ and $F$ refer to the evolution of predicted CES-D score as a function of GM volume change of the left and right amygdala, respectively. 
study in healthy adults, in which higher EPA and DHA intake was associated with greater GM volume in the subgenual anterior cingulate cortex, the right hippocampus, and the right amygdala. ${ }^{24}$ Our longitudinal study strengthens this cross-sectional result, suggesting that in older subjects, higher EPA intake may be associated with lower GM loss in the right amygdala.

These results corroborate our previous findings that EPA specifically (and not DHA, total n-3, or total n-6 PUFA) is associated with slower cognitive decline $^{25}$ and dementia risk, ${ }^{18}$ and also with lower depressive symptoms ${ }^{26}$ according to antidepressant effects documented in randomized controlled trials. ${ }^{27,28}$ Indeed, within the MTL, the rate of atrophy not only of the hippocampus, but also of adjacent structures such as the entorhinal cortex ${ }^{29}$ and the amygdala, ${ }^{30}$ is predictive of progression to dementia and $\mathrm{AD}$, because these regions develop neuropathology in the early stage of AD. ${ }^{31}$ Although left MTL atrophy seems to be the most consistent brain biomarker predicting conversion from $\mathrm{MCI}$ to $\mathrm{AD},{ }^{32}$ atrophy of the right MTL, including the amygdala, is also reported and may even be involved in earlier $\mathrm{AD}$ stages, thus enabling differentiation of normal subjects from subjects with MCI. ${ }^{33}$ Hence, in the ADNI cohort, atrophy of some right but not left MTL structures predicted subsequent decline in memory in cognitively unimpaired older subjects. ${ }^{34}$

Accordingly, we found that higher decline in global cognition was related to atrophy of the amygdala on the left side only, while atrophy of the right amygdala was related to decline in IST, a test exhibiting very early decline in prodromal AD. ${ }^{13}$ Therefore, the specific association found between EPA and the right MTL, also reported in a previous study in healthy adults, ${ }^{24}$ suggests that EPA may exert beneficial properties in early stages of dementia, which we were able to capture in our minimally cognitively impaired sample.

In addition, MTL atrophy may occur as a consequence of recurrent major depression. The amygdala, which is the core structure of the limbic emotionprocessing circuit, plays a key role in the regulation of mood and in the memory of emotional stimuli. ${ }^{35}$ Amygdala volume is significantly decreased in unmedicated depressed patients but increases after medication, supporting the neurotrophic hypothesis of antidepressant action. ${ }^{36}$ The reactivity of the right amygdala seems specifically altered in depression ${ }^{37}$ and may normalize with the use of selective serotonin reuptake inhibitors. ${ }^{38}$ Accordingly, more symptoms of depression were specifically related to atrophy of the amygdala in the right hemisphere in our study.

In our study, higher plasma EPA levels had a favorable association with right medial temporal struc- tures. EPA could exert neuroprotective effects through anti-inflammatory, neuroendocrine, or neurogenesis-related pathways (e-Discussion). Nevertheless, interpreting our results requires caution: 1) Probably because of limited power, we were not able to repeat the association between plasma EPA and clinical outcomes that we previously reported, and we could thus not test the hypothesis of a possible mediation by declining amygdala volume of such association. 2) Reasons for the relative specificity of relationship with EPA vs DHA remain speculative (e-Discussion). The main strengths of the present study include the 1) longitudinal MRI assessment of brain volume, 2) large population-based sample, 3) use of plasma fatty acid profiles to assess n-3 PUFA status, and 4) adjustment for many potential confounding variables, including vascular risk factors. Among potential limitations, plasma long-chain n-3 PUFA may reflect shorter-term dietary intake than do n-3 PUFA measured in erythrocyte membranes. However, stronger correlations have generally been reported between dietary long-chain PUFA and the proportion of long-chain PUFA in total plasma. ${ }^{39}$ Moreover, participants of this study who underwent MRI were probably healthier than those who did not, which may have biased cross-sectional associations, but this is less likely to have affected the longitudinal assessments. ${ }^{40}$ We cannot dismiss the possibility that drop-out between the $2 \mathrm{MRI}$ examinations may have generated bias in association measures; however, if present, it is more likely to have occurred toward an underestimation of associations, because we may have lost participants with worst nutritional status (thus lower n-3 PUFA) and higher brain atrophy. Finally, nonparticipation may hamper the external validity of the study, whose findings should not be generalized to the whole elderly population but only to those similar to the sample analyzed here.

Our finding of a relationship between plasma EPA and GM volume loss in the amygdala suggests that future clinical trials with EPA supplements could specifically target the volume of amygdala as an outcome measure.

\section{AUTHOR CONTRIBUTIONS}

C. Samieri performed statistical analyses and wrote the manuscript. P. Maillard performed SPM analyses and helped to write the manuscript. F. Crivello contributed to data collection and provided significant advice. C. Proust-Lima contributed to statistical analyses and provided significant advice. E. Peuchant contributed to determining plasma fatty acid proportions. C. Helmer contributed to experiment design, data collection, and provided significant advice. H. Amieva contributed to data collection and provided significant advice. M. Allard contributed to experiment design, data collection, obtained funding, and provided significant advice. J.F. Dartigues contributed to experiment design, data collection, obtained funding, and provided significant advice. S.C. Cunnane helped to write and revise the manuscript and provided significant advice. B. Mazoyer 
contributed to experiment design, data collection, obtained funding, and provided significant advice. P. Barberger-Gateau contributed to experiment design, data collection, obtained funding, helped to write the manuscript, and provided significant advice. All the authors read the draft critically. C. Samieri had full access to all of the data in the study and takes responsibility for the integrity of the data and the accuracy of the data analysis.

\section{STUDY FUNDING}

The 3C study is conducted under a partnership agreement between SanofiAventis and the Institut National de la Santé et de la Recherche Médicale (INSERM) and the Institut de Santé Publique et Développement of the Victor Segalen Bordeaux 2 University. The Fondation pour la Recherche Médicale (FRM) funded the preparation and initiation of the study. The 3C study is also supported by the Caisse Nationale Maladie des Travailleurs Salariés (CNAMTS), Direction Générale de la Santé (DGS), Mutuelle Générale de l'Education Nationale (MGEN), Institut de la Longévité, Regional Councils of Aquitaine and Bourgogne, Fondation de France, and Ministry of Research-INSERM Programme "Cohortes et collections de données biologiques." Fatty acid analyses performed by E. Peuchant were sponsored by the Conseil Régional d'Aquitaine. Dr Samieri was on a grant from the Ligue Européenne contre la Maladie d'Alzheimer (LECMA). Dr Proust-Lima received research support from ANR grant PRSP00601. The Canada Research Chairs, CFI, FRSQ, and CIHR, financed S.C.C.'s contribution to this paper. The study sponsors funded the preparation and initiation of the $3 \mathrm{C}$ study, as well as the data collection. They did not interfere in analysis and interpretation of the data, in writing the report, or in the decision to submit the paper for publication.

\section{DISCLOSURE}

C. Samieri, P. Maillard, F. Crivello, C. Proust-Lima, E. Peuchant, and C. Helmer report no disclosures. H. Amieva received speaker honoraria from GSK, UCB, and Novartis. M. Allard reports no disclosures. J.F. Dartigues reports research grants from Ipsen and Novartis, and speaker honoraria from Ipsen, Novartis, and Merck Serono. S.C. Cunnane and B. Mazoyer report no disclosures. P. Barberger-Gateau served on a scientific advisory board for Caisse Nationale pour la Solidarit é et l'Autonomie (CNSA); has received funding for travel and speaker honoraria from Lesieur, Bausch \& Lomb, Aprifel, Danone Institute, Canadian Association of Gerontology, and the Jean Mayer Human Nutrition Research Center on Aging, Tufts University; has received consultancy fees from Vifor Pharma; and receives research support from Lesieur, Danone, Agence Nationale de la Recherche, Conseil Régional d'Aquitaine, Institut Carnot LISA, and Groupe Lipides et Nutrition. Go to Neurology.org for full disclosures.

Received November 17, 2011. Accepted in final form March 21, 2012

\section{REFERENCES}

1. Fotuhi M, Mohassel P, Yaffe K. Fish consumption, longchain omega-3 fatty acids and risk of cognitive decline or Alzheimer disease: a complex association. Nat Clin Pract Neurol 2009;5:140-152.

2. Cunnane SC, Plourde M, Pifferi F, Begin M, Feart C, Barberger-Gateau P. Fish, docosahexaenoic acid and Alzheimer's disease. Prog Lipid Res 2009;48:239-256.

3. Yurko-Mauro K, McCarthy D, Rom D, et al. Beneficial effects of docosahexaenoic acid on cognition in age-related cognitive decline. Alzheimers Dement 2010;6:456-464.

4. Dangour AD, Allen E, Elbourne D, et al. Effect of 2-y n-3 long-chain polyunsaturated fatty acid supplementation on cognitive function in older people: a randomized, doubleblind, controlled trial. Am J Clin Nutr 2010;91:17251732.

5. Quinn JF, Raman R, Thomas RG, et al. Docosahexaenoic acid supplementation and cognitive decline in Alzheimer disease: a randomized trial. JAMA 2010;304:1903-1911.
6. Tan ZS, Harris WS, Beiser AS, et al. Red blood cell omega-3 fatty acid levels and markers of accelerated brain aging. Neurology 2012;78:658-664.

7. Three-City Study Group. Vascular Risk factors and risk of dementia: design of the Three-City Study and baseline characteristics of the study population. Neuroepidemiology 2003;22:316-325.

8. The FIL Methods Group. SPM8 Manual. London, UK, 2010. Available at: http://www.fil.ion.ucl.ac.uk/spm/doc/ manual.pdf. Accessed June 2012.

9. Lemaitre H, Crivello F, Dufouil C, et al. No epsilon4 gene dose effect on hippocampal atrophy in a large MRI database of healthy elderly subjects. Neuroimage 2005;24: 1205-1213.

10. Tzourio-Mazoyer N, Landeau B, Papathanassiou D, et al. Automated anatomical labeling of activations in SPM using a macroscopic anatomical parcellation of the MNI MRI single-subject brain. Neuroimage 2002;15:273-289.

11. Folstein MF, Folstein SE, McHugh PR. "Mini-mental state": a practical method for grading the cognitive state of patients for the clinician. J Psychiatr Res 1975;12:189198.

12. Isaacs B, Kennie AT. The Set test as an aid to the detection of dementia in old people. Br J Psychiatry 1973;123:467470

13. Amieva H, Le Goff M, Millet X, et al. Prodromal Alzheimer's disease: successive emergence of the clinical symptoms. Ann Neurol 2008;64:492-498.

14. American Psychiatric Association. Diagnostic and Statistical Manual of Mental Disorders: DSM-IV. Washington, DC: American Psychiatric Association; 1994.

15. Radloff LS. The CES-D scale: a self-report depression scale for research in the general population. Appl Psychol Meas 1977;1:385-401.

16. Berkman LF, Berkman CS, Kasl S, et al. Depressive symptoms in relation to physical health and functioning in the elderly. Am J Epidemiol 1986;124:372-388.

17. Fuhrer R, Rouillon F. La Version Française de l'Échelle CES-D (Center for Epidemiologic Studies-Depression Scale): description et traduction de l'échelle d'autoévaluation. Psychiatr Psychobiol 1989;4:163-166.

18. Samieri C, Feart C, Letenneur L, et al. Low plasma eicosapentaenoic acid and depressive symptomatology are independent predictors of dementia risk. Am J Clin Nutr 2008;88:714-21.

19. Proust-Lima C, Dartigues JF, Jacqmin-Gadda H. Misuse of the linear mixed model when evaluating risk factors of cognitive decline. Am J Epidemiol 2011;174:1077-1088.

20. Laird NM, Ware JH. Random-effects models for longitudinal data. Biometrics 1982;38:963-974.

21. Proust C, Jacqmin-Gadda H, Taylor JM, Ganiayre J, Commenges D. A nonlinear model with latent process for cognitive evolution using multivariate longitudinal data. Biometrics 2006;62:1014-1024.

22. Virtanen JK, Siscovick DS, Longstreth WT Jr, Kuller LH, Mozaffarian D. Fish consumption and risk of subclinical brain abnormalities on MRI in older adults. Neurology 2008;71:439-446.

23. Bowman GL, Silbert LC, Howieson D, et al. Nutrient biomarker patterns, cognitive function, and MRI measures of brain aging. Neurology 2012;78:241-249.

24. Conklin SM, Gianaros PJ, Brown SM, et al. Long-chain omega-3 fatty acid intake is associated positively with cor- 
ticolimbic gray matter volume in healthy adults. Neurosci Lett 2007;421:209-212.

25. Samieri C, Feart C, Proust-Lima C, et al. Omega-3 fatty acids and cognitive decline: modulation by ApoEepsilon 4 allele and depression. Neurobiol Aging 2011;32: 2317.e13-e22.

26. Feart C, Peuchant E, Letenneur L, et al. Plasma eicosapentaenoic acid is inversely associated with severity of depressive symptomatology in the elderly: data from the Bordeaux sample of the Three-City Study. Am J Clin Nutr 2008;87:1156-1162.

27. Parker G, Gibson NA, Brotchie H, Heruc G, Rees AM, Hadzi-Pavlovic D. Omega-3 fatty acids and mood disorders. Am J Psychiatry 2006;163:969-978.

28. Martins JG. EPA but not DHA appears to be responsible for the efficacy of omega-3 long chain polyunsaturated fatty acid supplementation in depression: evidence from a meta-analysis of randomized controlled trials. J Am Coll Nutr 2009;28:525-542.

29. Stoub TR, Bulgakova M, Leurgans S, et al. MRI predictors of risk of incident Alzheimer disease: a longitudinal study. Neurology 2005;64:1520-1524.

30. den Heijer T, Geerlings MI, Hoebeek FE, Hofman A, Koudstaal PJ, Breteler MM. Use of hippocampal and amygdalar volumes on magnetic resonance imaging to predict dementia in cognitively intact elderly people. Arch Gen Psychiatry 2006;63:57-62.

31. Horinek D, Varjassyova A, Hort J. Magnetic resonance analysis of amygdalar volume in Alzheimer's disease. Curr Opin Psychiatry 2007;20:273-277.

32. Ferreira LK, Diniz BS, Forlenza OV, Busatto GF, Zanetti MV. Neurostructural predictors of Alzheimer's disease: a meta-analysis of VBM studies. Neurobiol Aging 2011;32: 1733-1741.

33. Risacher SL, Saykin AJ, West JD, Shen L, Firpi HA, McDonald BC. Baseline MRI predictors of conversion from $\mathrm{MCI}$ to probable $\mathrm{AD}$ in the $\mathrm{ADNI}$ cohort. Curr Alzheimer Res 2009;6:347-361.

34. Murphy EA, Holland D, Donohue M, et al. Six-month atrophy in MTL structures is associated with subsequent memory decline in elderly controls. Neuroimage 2010;53: $1310-1317$.

35. Krishnan V, Nestler EJ. The molecular neurobiology of depression. Nature 2008;455:894-902.

36. Hamilton JP, Siemer M, Gotlib IH. Amygdala volume in major depressive disorder: a meta-analysis of magnetic resonance imaging studies. Mol Psychiatry 2008;13:9931000.

37. Suslow T, Konrad C, Kugel H, et al. Automatic moodcongruent amygdala responses to masked facial expressions in major depression. Biol Psychiatry 2010;67:155-160.

38. Windischberger C, Lanzenberger R, Holik A, et al. Areaspecific modulation of neural activation comparing escitalopram and citalopram revealed by pharmaco-fMRI: a randomized cross-over study. Neuroimage 2010;49:11611170.

39. Hodson L, Skeaff CM, Fielding BA. Fatty acid composition of adipose tissue and blood in humans and its use as a biomarker of dietary intake. Prog Lipid Res 2008;47:348380.

40. Harald K, Salomaa V, Jousilahti P, Koskinen S, Vartiainen E. Non-participation and mortality in different socioeconomic groups: the FINRISK population surveys in 1972-92. J Epidemiol Community Health 2007;61:449-454.

\section{Neurology ${ }^{\circledR}$ Launches Subspecialty Alerts by E-mail!}

Customize your online journal experience by signing up for e-mail alerts related to your subspecialty or area of interest. Access this free service by visiting http://www.neurology.org/site/subscriptions/ etoc.xhtml or click on the "E-mail Alerts" link on the home page. An extensive list of subspecialties, methods, and study design choices will be available for you to choose from—allowing you priority alerts to cutting-edge research in your field!

Neurology ${ }^{\circledR}$ Online CME Program
Earn CME while reading Neurology. This program is available only to online Neurology
This will provide all of the information necessary to get started. The American Academy of
Neurology (AAN) is accredited by the Accreditation Council for Continuing Medical Education
(ACCME) to sponsor continuing medical education for physicians. Neurology is planned and
produced in accordance with the ACCME Essentials. For more information, contact AAN Member
Services at $800-879-1960$.

